\title{
Childhood obesity and impulsivity: An investigation with performance-based measures
}

Citation for published version (APA):

Verbeken, S., Braet, C., Claus, L., Nederkoorn, C., \& Oosterlaan, J. (2009). Childhood obesity and impulsivity: An investigation with performance-based measures. Behaviour Change, 26(3), 153-167. https://doi.org/10.1375/bech.26.3.153

Document status and date:

Published: 01/01/2009

DOI:

10.1375/bech.26.3.153

Document Version:

Publisher's PDF, also known as Version of record

Document license:

Taverne

Please check the document version of this publication:

- A submitted manuscript is the version of the article upon submission and before peer-review. There can be important differences between the submitted version and the official published version of record.

People interested in the research are advised to contact the author for the final version of the publication, or visit the DOI to the publisher's website.

- The final author version and the galley proof are versions of the publication after peer review.

- The final published version features the final layout of the paper including the volume, issue and page numbers.

Link to publication

\footnotetext{
General rights rights.

- You may freely distribute the URL identifying the publication in the public portal. please follow below link for the End User Agreement:

www.umlib.nl/taverne-license

Take down policy

If you believe that this document breaches copyright please contact us at:

repository@maastrichtuniversity.nl

providing details and we will investigate your claim.
}

Copyright and moral rights for the publications made accessible in the public portal are retained by the authors and/or other copyright owners and it is a condition of accessing publications that users recognise and abide by the legal requirements associated with these

- Users may download and print one copy of any publication from the public portal for the purpose of private study or research.

- You may not further distribute the material or use it for any profit-making activity or commercial gain

If the publication is distributed under the terms of Article $25 \mathrm{fa}$ of the Dutch Copyright Act, indicated by the "Taverne" license above, 


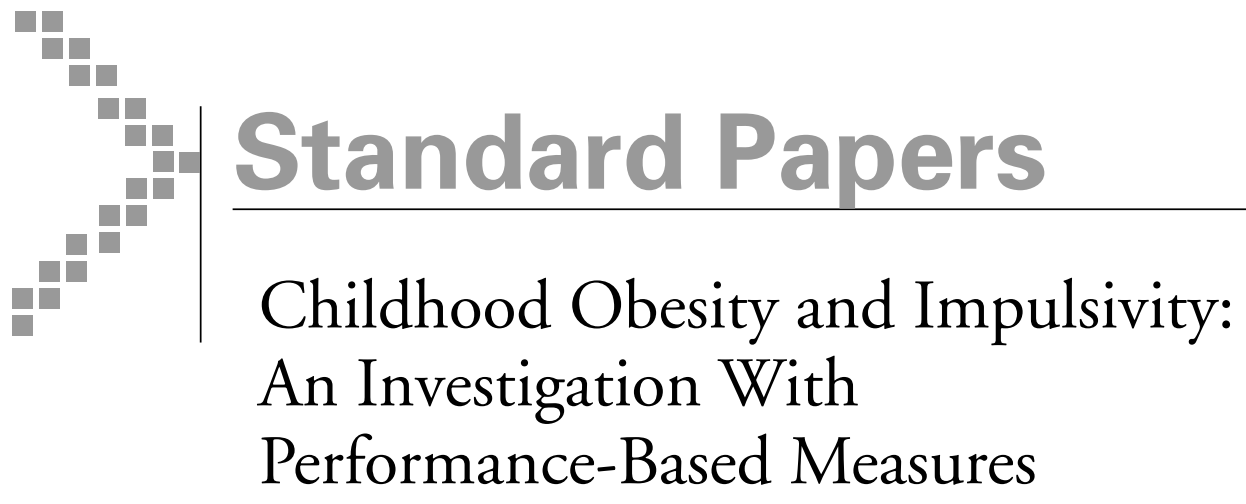

\author{
Sandra Verbeken,' Caroline Braet,' Line Claus,' Chantal Nederkoorn² \\ and Jaap Oosterlaan ${ }^{3}$ \\ I Ghent University, Belgium \\ 2 Maastricht University, the Netherlands \\ ${ }^{3}$ Amsterdam University, the Netherlands
}

\begin{abstract}
The study investigated whether obese children are more impulsive than lean children, taking into account the multidimensionality of the construct. Responses of 41 overweight children were compared to those of 40 lean children. The Stop Task, Circle Drawing Task and Opposite Worlds Task were administered to measure executive inhibitory control, and the Maudsley Index of Childhood Delay Aversion and the Door Opening Task were administered to measure motivational inhibitory control. On the Stop Task, the overweight children showed less inhibitory control. On the Opposite Worlds task, we found no significant difference, whereas on the Circle Drawing Task an unexpected group difference was found. Although on the Door Opening Task the overweight children showed greater reward sensitivity, they were equally motivated to wait on the Maudsley Index of Childhood Delay. We conclude that the findings were different depending on the measure used, but that they suggest that overweight children can be characterised by a decrease in executive and motivational inhibitory control.
\end{abstract}

Keywords: obesity, children, impulsivity, performance-based measures

In adults, considerable research points to the relationship between impulsivity and food intake (Guerrieri et al., 2007; Guerrieri, Nederkoorn, \& Jansen, 2007; Nasser, Gluck, \& Geliebter, 2004; van den Bree, Przybeck, \& Cloninger, 2006), between impulsivity and obesity (Fassino, Leombruni, Piero, Daga, Amianto, \& Rovera, 2002; Gunstad, Paul, Cohen, Spitznagel, \& Gordon, 2007; Ryden, Sullivan, Torgerson, Karlsson, Lindroos, \& Taft, 2003; Nederkoorn, Smulders, Havermans, Roefs, \& Jansen, 2006) and between impulsivity and boulimia nervosa (BN) and Binge Eating Disorder (BED) (Brewerton, Hand, \& Bishop, 1993; Bullik, Sullivan, Weltzin, \& Kaye, 1995; Engel et al., 2005; Fassino, Daga, Piero, Leombruni, \& Rovera, 2001; Nederkoorn, Van Eijs, \& Jansen, 2004; Rosval, Steiger, Bruce, Israël, Richardson, \& Aubut, 2006). Furthermore, research shows parallels between obesity and other potentially addictive behaviours in adults, all characterised by impulsive

Address for correspondence: Sandra Verbeken, Department of Developmental, Personality and Social Psychology, Ghent University, H. Dunantlaan 2, 9000 Ghent, Belgium. E-mail: Sandra.Verbeken@UGent.be 
behaviour and a rise in sensitivity to reward (Davis, Patte, Levitan, Reid, Tweed, \& Curtis, 2007; Davis, Strachan, \& Berkson, 2004; Dawe \& Loxton, 2004).

Yet, the mechanisms of how impulsivity operates are less clear. Living under conditions of abundance means living with the continuous temptation of the immediately rewarding value of palatable, high-caloric foods. Resisting temptation requires self-regulatory resources. As a result, overeating may be promoted by a lack of self-regulation skills, allowing impulses and immediate reward to rule over longterm consequences (van den Bos \& de Ridder, 2006). Indeed, there is a remarkable similarity between impulsive behaviour and obesigenic eating patterns such as the inability to eat on a regular basis, to postpone in-betweens and to resist urges to indulge in snacks (Lyke \& Spinella, 2004).

Although younger people appear to experience higher levels of impulsivity in general, and therefore may be more likely to make impulsive choices related to food (Lyke \& Spinella, 2004), the link between impulsivity and being overweight in children is far less studied. Some research found that a subgroup of overweight children demonstrated an impulsivity-prone personality, that this subgroup act more on impulse than normal weight children, and that impulsivity hinders weight loss in therapy (Nederkoorn, Braet, Van Eijs, Tanghe, \& Jansen, 2006; Nederkoorn, Jansen, Mulkens, \& Jansen, 2007). Overweight children starting treatment for obesity in a paediatric centre were found to display personality traits frequently associated with impulsive behaviour. They were found to be more impulsive and hyperactive and less attentive compared to control children who showed more reflectivity (Braet, Claus, Verbeken, \& Van Vlierberghe, 2007). Furthermore, in a delay-of-gratification task, it seems to be more difficult for overweight children to wait since they more often choose the smaller immediate reward than the larger delayed reward (Bonato \& Boland, 1983; Johnson, Parry, \& Drapman, 1978; Lewitts, \& Israel, 1978; but see Bourget \& White, 1984; Wilson, 1980). Finally, studies point to the comorbidity between obesity and attention/hyperactivity disor$\operatorname{der}(A D H D)$ in children (Agranat-Meged et al., 2005; Holtkamp et al., 2004). Therefore, since the prevalence of childhood obesity is rising (Reilly, 2006; Reilly, 2007; Wang \& Lobstein, 2006) and as children are the most important group in terms of prevention to curb or even reverse the epidemic of obesity, they are a worthwhile group to study to determine the possible influence of impulsivity on eating behaviour.

The study of impulsivity is complicated since it is not a unidimensional construct but involves a number of processes: the capacity to tolerate delay for reward, to inhibit an already initiated response, and to estimate the passage of time (Dougherty, Mathias, Marsh, \& Jagar, 2005). Therefore, it is important to distinguish between the different processes of impulsivity that might be related to overeating. Two measurement paradigms seem to capture the different component processes related to the construct of impulsivity: (1) the rapid-decision paradigms evaluating the executive inhibition effects and (2) the reward-directed paradigms evaluating motivational inhibition effects (Dougherty et al., 2003; Nigg, 2000; Sonuga-Barke, 2003). In the rapid-decision paradigms, executive inhibitions are defined as processes for intentional control in the service of higher order or longer term goals (Nigg, 2000). In this, three different forms of executive inhibition can be discerned: prepotent inhibition, sustained inhibition and interference control (Barkley, 1997; Nigg, 2000). Within the reward-directed paradigms, the focus is on evaluating motivated inhibition of behaviour or thought. The study of inhibitory 
processes operating in different incentive contexts has been performed in several ways. The delay aversion model (Sonuga-Barke, 1994) is one approach, which conceptualises impulsive behaviour within a motivational framework. This theory views an impulsive choice as the preference for a small immediate reward over a large delayed reward, because the child does not tolerate the delay necessary for the larger reward (Dougherty et al., 2003; Nichols \& Waschbusch, 2004). Another way to study motivational inhibitory control is by measuring 'gambling' behaviour, which is behaviour driven by the strong short-term effects of immediate reward, neglecting the negative long-term effects of an action.

Through the use of self-report questionnaires, the focus in previous studies on impulsivity in overweight children lies mainly on trait impulsivity (Lyke \& Spinella, 2004; Nederkoorn et al., 2006; Ryden et al., 2004). Behavioural approaches or performance-based measures, on the other hand, may have the advantage of being sensitive to transient changes in impulsivity processes and are less subject to demand characteristics (Dougherty et al., 2003; Nederkoorn et al., 2006). The present investigation aims to compare the response of overweight children to that of normal weight children on different performance-based tasks, measuring multiple kinds of inhibitory processes. All these measurements have shown good test-retest reliability in previous studies (Kindlon, Mezzacappa, \& Earls, 1995; Kuntsi, Stevenson, Oosterlaan, \& Sonuga-Barke, 2001; Manly, Anderson, Nimmo-Smith, Turner, Watson, \& Robertson, 2001).

Within the rapid-decision paradigms, three different tasks were selected for they may each tap a different form of executive inhibition (Barkley, 1997; Nigg, 2000). First, the Stop Task (Logan \& Cowan, 1984) is a measure of prepotent inhibition. The task examines a child's ability to stop a prepotent motor response, which means a response that is, or has been previously, associated with reinforcement. It is a unique measure of inhibition in that it permits an estimation of the latency of the inhibitory process (Castellanos, Sonuga-Barke, Milham, \& Tannock, 2006). Second, the Circle Drawing Task (Bachorowski \& Newman, 1985, 1990), a measure of sustained inhibition, investigates the ability of the child to inhibit an ongoing response, which allows for a delay in the decision to continue responding. It is advantageous to include a continuous motor task because continuous motor sequences are quite different to discrete movements (Bachorowski \& Newman, 1990). Finally, the Opposite Worlds Task (Manly et al., 2001) is a stimulus-incompatibility task, used to examine interference control. This task requires controlling an interfering prepotent or automatic verbal response to carry out an effortful primary response (Nigg, 2000). Investigators point to the value of these tasks for the assessment of impulsivity-related disorders, such as Attentiou Deficit/Hyperactivity Disorder (ADHD) and Oppositional Defiant Disorder (ODD) in children (Avila, Cuenca, Felix, Parcet, \& Miranda, 2004; Geurts, Verté, Oosterlaan, Roeyers, \& Sergeant, 2004; Lijffijt, Kenemans, Verbaten, \& van Engeland, 2005; Oosterlaan \& Sergeant, 1998; Schachar et al., 2007). In the field of eating disorders and obesity studies, the use of rapid decision tasks is scarce. One study using the Stop Task suggests that restrained eaters are worse in inhibiting their motor responses than unrestrained eaters (Nederkoorn, Van Eijs, \& Jansen, 2004). Similarly, one study in obese children suggests that children with obesity inhibit less often on a Stop Task compared to children with normal weight (Nederkoorn et al., 2006).

To tap the motivational inhibitory processes, two different tasks were selected. The Maudsley Index of Childhood Delay Aversion (Kuntsi et al., 2001) is a poten-

\section{Behaviour Change}


tial instrument used to measure impulsive responding resulting from delay aversion, and second, the Door Opening Task, which covers reward-directed behaviour with blindness for the long-term consequences of that behaviour (Daugherty \& Quay, 1991). Recent investigations demonstrate the utility of reward-directed paradigms for measuring impulsive behaviour in children with ADHD and Conduct Disorder (CD) (Daugherty \& Quay, 1991; Matthys, van Goozen, de Vries, Cohen-Kettenis, \& van Engeland, 1998; Matthijs, van Goozen, Snoek, \& van Engeland, 2004; Neef et al., 2005; Nichols \& Waschbusch, 2004; Solanto et al., 2001; Wilson \& Evans, 2002). Furthermore, Nederkoorn and colleagues (Nederkoorn et al., 2006) suggested, using the Door Opening Task, that obese children in treatment are indeed more sensitive to reward than children with normal weight.

To conclude, impulsivity is a multidimensional construct that has been defined and measured in many ways. Until now, no comprehensive impulsivity research in overweight children has been conducted. The current study improves on previous research by using an extensive battery of impulsivity measurements that covers the major inhibitory processes. As a result, this type of research may help us to understand what specific inhibitory process hinders self-regulation in overweight children.

The purpose of this investigation is to address this need by comparing the performance of overweight children to that of normal weight control children on several different tasks within the two types of impulsivity paradigms. Based on the few studies that have been conducted before in the field of childhood obesity, we hypothesise that the overweight group will exhibit greater impulsive responding than the control group across all tasks: they will show less executive inhibitory control, prefer to wait less, be more sensitive to reward and keep gambling longer than children with normal weight.

\section{Method}

\section{Participants and procedure}

Overweight children ( $N=41$ children, 16 boys and 25 girls $)$ admitted in a medical paediatric centre for treatment for obesity were invited to participate. Nobody refused. Inclusion criteria were: diagnosed as primary obesity, displaying an adjusted BMI above $120 \%$, between 10 and 14 years old, attending regular schools corresponding with IQ within the normal range, and absence of Pervasive Development Disorder. The mean age was 12.0 years $(S D=1.46)$, the mean height and weight were $156.29 \mathrm{~cm}(S D=9.55)$ and $78.9 \mathrm{~kg}(S D=18.98)$ respectively. The adjusted BMI ranged from $125.42 \%$ to $273.92 \%$ (CDC BMI z-scores range from 1.16 to 2.83 ; Ogden et al., 2002). All socioeconomic strata were represented in the overweight group (upper and upper-middle class: $23.4 \%$; middle class: $48.7 \%$; lower-middle and lower class: $17.9 \%$ ) (Hollinghead \& Redlich, 1958; Hollinghead, 1975).

The normal weight control children $(N=41,17$ boys and 23 girls $)$ were selected from primary and secondary regular schools. They were matched on age and gender with the children in the experimental group. One girl was excluded from the analyses because her adjusted BMI was above 120\% (136.66 \%). The mean age was 11.6 years $(S D=1.36)$. Their mean height and weight were $149.99 \mathrm{~cm}(S D=10.89)$ and $37.69 \mathrm{~kg}(\mathrm{SD}=6.86)$ respectively. The adjusted $\mathrm{BMI}$ ranged from $73.05 \%$ to $115.40 \%$ (CDC BMI $z$-scores range from -3.02 to 0.82; Ogden et al., 2002). All socioeconomic strata were represented in the control group (upper and upper- 
middle class: 21\%; middle class: 50\%; lower-middle and lower class: 29\%) (Hollinghead \& Redlich, 1958, Hollinghead, 1975).

Both samples did not differ according to age, gender and socioeconomic background.

The local research ethics committee approved the protocol of this study. During a test session of approximately 2 hours, each child was tested individually in a lowstimuli room. The child completed the performance-based measures after answering the questions from the ADHD module of the KID-SCID interview. Standardised instructions were used for each of the tasks. The tasks were administered in three blocks: The Maudsley Index of Childhood Delay Aversion (block 1), Stop Task (block 2) and OW- TEA-Ch, Circle Drawing Task and Door Opening Task (block 3). To minimise the potential for fatigue effects, the order of the blocks was counterbalanced over the children for each group. During a short break the children were offered a drink and at the end of the session they were debriefed and all received the same reward.

\section{Measures}

Body overweight. The BMI (weight/height ${ }^{2}$ ) was calculated for each child. In order to make BMI comparisons between obese children of different ages, the adjusted BMI was used in this study. The formula is [Actual BMI/Percentile 50 of BMI for age and gender] $\times 100$. The 50 th percentiles of the BMI were based on European normative data (Fredriks, van Buuren, Wit, \& Verloove-Vanhorick, 2000).

The Structured Clinical Interview for DSM-IV, Childhood version (KID-SCID; Hien et al., 1994, 1998; Dutch version: Dreessen, Stroux, \& Weckx, 1998) was used to assess DSM-IV disorders in children. Similar to the adult version, the KID-SCID is a semistructured instrument designed to generate childhood DSM-IV diagnoses for clinical research studies. In the current study, only the ADHD module that is part of the disruptive behaviour disorders section was assessed using the children as informants. The first part of the ADHD-module assesses nine criteria referring to attention deficit problems. The second part of the module assesses hyperactivity (six items) and impulsivity symptoms (three items). Each criterion is scored as present (' 1 ' score) or absent (' 0 ' score). In case of doubt, the criterion in question is assigned a ' 0 ' score. In the study of Timbremont, Braet \& Dreessen (2004) child-parent agreement rates varied between $88.7 \%$ and $100 \%$, which indicates a good interview reliability. In addition, preliminary results of a study by Matzner and colleagues (Matzner, Silva, Silvian, Chowdhury, \& Nastasi, 1997) showed fair to excellent test-retest reliability for the disruptive behaviour disorders module ( $\alpha$ between .63 and .84). Pilot data also indicated excellent interrater reliability for the disruptive behaviour module ( $\alpha=1.0$ for ADHD) (Matzner, 1994). In this study, Cronbach $\alpha$ internal consistency coefficients were 0.82 for the attentional deficit subscale, 0.74 for the hyperactivity subscale, and 0.63 for the impulsivity subscales respectively.

Opposite Worlds of the Test of Everyday Attention for Children (OW-TEA-Ch; Manly et al., 2001). This subtest of the TEA-Ch was used as a measure of verbal inhibition. It is a stimulus-incompatibility task, used here to examine interference control. The child was required to suppress an automatic or prepotent verbal response. There are two conditions in the OW-TEA-Ch. In the Same World (neutral) condition, the child names the numbers 1 and 2 in a snake-like trail. In the Opposite World (suppression) condition, the child is instructed to say 'two' when a

\section{Behaviour Change}


1 is designated and say 'one' when a 2 is designated on the trail. The experimenter pointed to each digit, only moving onto the next when a correct response was given. Each condition was performed twice. The dependent variable was the difference between the mean time needed to complete two neutral conditions and the mean time needed to complete two suppression conditions. This dependent variable will be referred to as the 'OW-TEA-Ch-Time Difference'. The smaller the OWTEA-Ch-Time Difference, the better the participant was able to suppress the automatic verbal response.

The Circle Drawing Task (Bachorowski \& Newman, 1990). The Circle Drawing Task was used as a measure of inhibition of an ongoing response. The task requires the subjects to trace a large printed circle with their index finger. The circle is 50.80 $\mathrm{cm}$ (20 in.) in diameter, drawn on a cardboard square, and covered with plexiglass. The circle has a small line indicating the starting and the finishing points of the tracing. The task was administered under two conditions: first with neutral instructions ('trace the circle') followed by inhibition-instructions ('trace the circle again, but this time as slowly as you can'). A maximum of 12 minutes was allowed for both tracing conditions. Participants were not informed of this fact. The dependent variable in this task was the time used to trace the circle in the slow condition minus the tracing time in the neutral condition. This dependent variable will be referred to as 'Circle Time Difference'. The larger the Circle Time Difference, the better a participant was able to inhibit (slow down) the continuous tracing response.

The Stop Task (Logan \& Cowan, 1984; Logan, Cowan, \& Davis, 1984 the original version; Oosterlaan, Logan, \& Sergeant, 1998). This computer task provides an index of the child's ability to inhibit a prepared motor response. The task was presented as a game in which the child had to perform the tasks of an air traffic controller. First, the child was taught to respond to airplanes appearing on the computer screen by pressing the response button that was on the same side as the airplane (a two-choice reaction time task). Then, the child was told to withhold responding whenever he or she saw a big white cross (the 'stop' trials), but otherwise to keep on responding to the planes as quickly as possible (the 'go' trials). Each trial began with a 350 milliseconds presentation of a fixation point ('+'-sign presented at the centre of the screen). The presentation of the stimulus (an airplane), displayed for 1500 milliseconds then followed. The intertrial interval was 1000 milliseconds. The stimuli appeared equally often on either side of the screen within each block. The stop signals (white crosses) appeared at the centre of the screen, c.q. on top of the airplane. They were presented equally often after left- and right-sided presentations of the stimuli. A go trial always followed a stop trial, except once in each block where two stop signals were presented in succession. The percentage of stop trials was $25 \%$. A tracking algorithm (for a detailed description of this procedure, see Scheres et al., 2003) was applied to vary the delay between the go and the stop signal. The longer this delay, the harder it is to inhibit the response.

All children performed two practices and four experimental blocks (each consisting of 64 trials) on this task and were given short breaks between blocks. The main dependent variable in this task was the stop signal reaction time (SSRT). The speed of the stopping process, the SSRT cannot be observed, because the response to a stop signal is a covert one. The SSRT can be estimated using the race model (Logan, Cowan, \& Davis, 1984). According to this model the probability of inhibiting the response depends on the outcome of a race between the 'go' process and the 
stopping process. The process that finishes first wins the race. If the go process is faster than the stopping process, the child emits the response; if the stop process finishes first, the response is inhibited. The outcome of the race depends on the speed and the variability of the go process, the delay between the go stimulus and stop signal, and the speed and the variability of the stop process. By using the tracking mechanism, success rate on inhibition trials is .5. This means that SSRT can be calculated by subtracting the mean delay from the mean go signal reaction time (Scheres et al., 2003).

The Door Opening Task (Daugherty and Quay, 1991; Nederkoorn, personal communication). The task provides a measure of motivational inhibition. It consists of a series of 100 doors presented sequentially on a laptop computer in a preprogrammed order of winning and losing doors. The probability of a winning door appearing, decreases by $10 \%$ with each succeeding set of 10 doors and starts at $90 \%$ (thus from $90 \%$ to $0 \%$ ). Within each set of 10 doors, losing doors are randomly sequenced among winning doors. In this game, the subject chooses either to open the next door or to stop playing and there is a steadily increasing ratio of punished responses (sad face behind door) to rewarded responses (happy face behind door). The dependent measures were the total number of doors opened (Doors Opened) and the total number of doors opened divided into three categories (Door Selection Strategies): (1) opening a total of 1 to 31 doors resulted in winning a suboptimal amount of points (10-29 points), due to a conservative selection approach; (2) 32 to 64 doors opened resulted in an optimal strategy, with a maximum gain of points (3035 points); and opening of 65 to 100 doors resulted in a suboptimal amount of points earned (29-10 points), due to a perseverative selection strategy. A large number of doors opened are indicative of reward sensitivity and response perseveration. Subjects more sensitive to punishment will stop opening doors after a few punished responses.

The Maudsley Index of Childhood Delay Aversion (Kuntsi et al., 2001). This computer task was originally designed to test the delay aversion hypothesis that children with ADHD choose immediate, small rewards over large, delayed ones, when this leads to less overall delay (Sonuga-Barke, Taylor, Sembi, \& Smith, 1992). The child has to make a choice, on 20 occasions, between a small immediate reward (1 point involving a 2 second prereward delay) and a larger delayed reward ( 2 points involving a 30 second prereward delay). If the child chooses the small reward, the next trial started immediately afterwards. The task, administered on a laptop computer, was presented as a space game, in which the child, as a captain of a space ship, had to destroy enemy spacecraft (using the computer mouse). The aim of the game was to earn as many points as possible. Before the experimental trials, the child first practiced using the mouse and choosing each of the rewards. The tester also asked the child questions about the game in order to ensure that he or she understood the rules and aims of the game. The dependent variable used in the analyses was the percentage of choices for the 2-point delayed reward and will be referred to as 'Delay Aversion'.

\section{Statistical Analyses}

First, correlations were calculated between the different impulsivity measures. Next, all correlations with age were explored.

Analysis of variance (ANOVA/MANOVA) and chi-square tests were used to assess differences between overweight children versus children with normal weight.

\section{Behaviour Change}


We controlled for age because executive functions are still developing in the age range of 9-15 and this might influence the outcome despite the fact that there were no group differences for age. The analyses of the group contrast were repeated with gender as fixed factor. There were no significant differences found.

Two children in the control group received the diagnoses of ADHD. When the data of these children were excluded, the pattern of results of the group comparisons on the impulsivity measures did not alter. Therefore, the analyses on all subjects were reported.

\section{Results}

The results of the data analyses are presented in Tables 1 and 2 and Figure 1.

\section{Correlations Between Dependent Measures}

Scores for some of the variables were reflected so that for all of the variables, the larger the score, the greater the level of impulsivity. The matrix reveals a pattern of low to moderate $(r<.30)$, but not all positive, correlations among the various impulsivity measures. Overall, the correlations ranged from $|.01|$ to $|.31|$. These results indicate that the individual impulsivity measures were not highly correlated with each other. None of the performance-based measures of impulsivity were correlated with age.

\section{Executive Inhibitions}

The Opposite Worlds of the Test of Everyday Attention for Children. There was no significant group difference for the verbal inhibition score (OW-TEA-Ch-Time Difference), $F(1,78)=.02, p=.89$.

Circle Drawing Task. This task showed a significant group difference for inhibition time (Circle Time Difference), $F(1,78)=7.92, p<.01 ; \eta^{2}=.09$, but in an unexpected direction. The normal weight controls had smaller difference scores, indicating more problems with inhibition of the continuous tracing response than the children in the overweight group.

Stop Task. A MANOVA with SSRT and RT as dependent variables showed a significant effect of group, Wilks' $\lambda=.91, F(2,70)=3.58, \mathrm{p}<.05, \eta^{2}=.09$. As predicted, the overweight group had slower SSRTs compared to the control group, indicating less efficient inhibitory control, $F(2,70)=9.75, p<.01, \eta^{2}=.11$. There

\section{TABLE 1}

Pearson Correlations Between the Dependent Variables, Age and IQ

\begin{tabular}{lrrrrrrr}
\hline & 1 & 2 & 3 & 4 & 5 & Age & IQ \\
\hline OW-TEA-Ch-Time Difference & .12 & & & & & -.17 & .08 \\
Circle Time Difference CD & -.08 & .18 & & & & -.11 & -.19 \\
SSRT Stop task & .19 & $.31^{* *}$ & -.18 & & & -.16 & -.08 \\
Doors Opened DOT & .15 & -.01 & -.14 & .17 & & -.06 & -.02 \\
Delay Aversion MIDA & .11 & -.17 & .01 & .17 & -.14 & -.16 & -.14 \\
\hline
\end{tabular}

Note: OW-TEA-Ch = Opposite Worlds of the Test of Everyday Attention for Children; SSRT = stop signal reaction time; DOT = Door Opening Task; MIDA = Maudsley Index of Childhood Delay Aversion. ${ }^{*} p<.05,{ }^{* *} p<.01,{ }^{* * *} p<.001$. 
Means, Standard Deviations, F-values for the Two Groups for the Dependent Variables

\begin{tabular}{lccc} 
& $\begin{array}{c}\text { Control group } \\
M(S D)\end{array}$ & $\begin{array}{c}\text { Overweight group } \\
M(S D)\end{array}$ & $F(1,79)$ \\
\hline $\begin{array}{l}\text { Opposite Worlds Task } \\
\text { OW-TEA-Ch-Time Difference }\end{array}$ & $2.47(1.42)$ & $2.33(2.07)$ & 0.02 \\
$\begin{array}{l}\text { Circle Drawing Task } \\
\text { Circle Time Difference }\end{array}$ & $57.14(43.91)$ & $90.87(58.11)$ & $7.92^{* *}$ \\
$\begin{array}{l}\text { Stop Task } \\
\text { SSRT }\end{array}$ & $227.00(47.69)$ & $261.93(63.01)$ & $9.75^{* *}$ \\
$\quad$ RT & $546.45(90.53)$ & $543.65(95.62)$ & 0.08 \\
\hline $\begin{array}{l}\text { Door Opening Task } \\
\text { Doors Opened }\end{array}$ & $29.70(20.03)$ & $51.27(26.12)$ & $18.57^{* * *}$ \\
$\begin{array}{l}\text { Maudsley Index of Childhood } \\
\text { Delay Aversion } \\
\quad \text { Delay Aversion }\end{array}$ & $68.56(27.04)$ & $72.20(20.83)$ & 0.24 \\
\hline
\end{tabular}

Note: OW-TEA-Ch = Opposite Worlds of the Test of Everyday Attention for Children; SSRT = stop signal reaction time. ${ }^{*} p<.05,{ }^{* *} p<.01,{ }^{* * *} p<.001$.

were no significant differences between the groups on reaction times on the go-trials $F(2,70)<1$, indicating that there were no impairments in responding itself.

\section{Motivational Inhibitions}

The Door Opening Task. An ANOVA showed a significant effect of group for the total amount of doors opened (Doors Opened), $F(1,78)=18.57, p<.001$. The proportion of children that opened doors in a conservative, optimal, or perseverative way is displayed in Figure 1. A chi square analysis was performed with group as the independent variable and Door Selection Strategies as the dependent variable. The groups differed with regard to the selection of cards, $\chi^{2}(2, N=81)=15.48, p<.001$. Comparison of either the conservative or the perseverative strategy with the optimal door selection strategy, indicated that compared to the normal controls, more children in the overweight group used a perseverative door selection strategy, $\chi^{2}(1, N=53)=4.61, p<$ .05 and less a conservative door selection strategy, $\chi^{2}(1, N=66)=6.04, p<.05$.

The Maudsley Index of Childhood Delay Aversion. The group comparisons were nonsignificant for the percentage of choices for the larger reward, $F(1,78)=.24$, $p=$ $.63 ; \eta^{2}=.00$.

\section{Discussion}

The main purpose of this study was to determine whether overweight children act more on impulse than normal weight controls. We examined performance-based differences on five tasks, related to two behavioural measurement paradigms. It was hypothesised (1) that overweight children have less executive inhibitory control and (2) are more sensitive to reward than children with normal weight.

The results of the performance-based tasks showed that different processes seem to underlie the impulsive behaviour in overweight children, confirming the multi-

\section{Behaviour Change}


dimensionality of the concept of impulsivity. Both the executive inhibition and motivational inhibition paradigms have demonstrated utility in the characterisation of possible deficits in overweight children.

The study first explored possible deficits in executive inhibitions via the Stop Task. The task seems to provide a remarkable differentiation between children who are or are not overweight. The overweight children showed longer SSRTs indicating less efficient executive inhibitory control.

Unlike our expectations, the overweight children performed equally well on the inhibition of a verbal response, an indication of interference control (Opposite Worlds Task). A possible explanation lies in the specification of the task. The current study examined the basic process of interference control with a regular stimulus-incompatibility task. However, Nigg (2000) points at the role of motivational systems moderating interference control for emotionally significant stimuli. Indeed, in previous research using an emotional Stroop task (Braet \& Crombez, 2003), children with obesity displayed interference deficits and were slower in naming food words versus control words. Furthermore, the children with obesity showed no interference effect for negative-emotion words. These findings support the idea that possible self-regulatory deficits in overweight children are stimulus-specific.

Contrary to our hypotheses, the overweight children performed better on the inhibition of an ongoing, continuous motor response (Circle Drawing Task) than the children with normal weight. Since this result was not due to baseline differences, the normal children actually showed decreased inhibition compared to over-

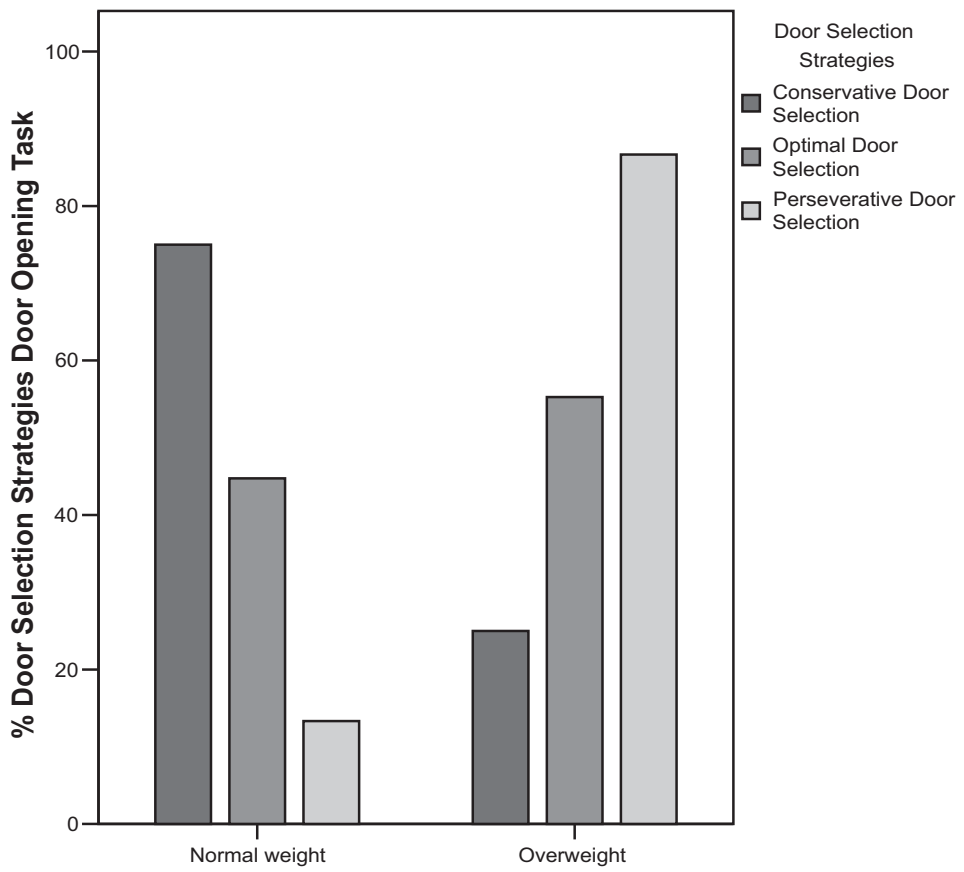

\section{FIGURE 1}

Percentage of conservative, optimal, or perseverative door selection on the Door Opening Task by children with normal weight and overweight. 
weight children. We do not have a clear explanation for this unexpected finding. Bacharowski \& Newman (1990) found that anxiety may have a restraining influence on motor speed in the presence of a goal (finishing point of the tracing). Possibly, the presence of anxiety may explain the superior performance of the children in the overweight group on the Circle Drawing Task. Preliminary studies (Vila et al., 2004) show that overweight children are indeed more vulnerable to emotional problems. However, we did not control for emotional functioning.

Within the reward-directed paradigm the Door Opening Task is a commonly used task. The present findings indicate that the task offers an effective means of discrimination between children who are and are not overweight. The overweight children kept gambling longer despite increasing losses, suggesting greater reward sensitivity and response perseveration. This endorses the observation that for overweight children it is more difficult to resist the temptation of tasty food than for lean children, despite the long-term negative consequences of overeating (van den Bos et al., 2006). Findings based on self-report have also confirmed the role of reward sensitivity in the development of obesity. It has been proposed that reward sensitivity may contribute to greater sensitivity and attention towards food-related cues (Dawe \& Loxton, 2004) and a preference for sweet and fatty food (Davis et al., 2007). These findings stress the contribution of motivational inhibitory processes in overweight children.

Finally and unexpectedly, delay aversion measured with the Maudsley Index of Childhood Delay Aversion did not differ between the groups. The overweight children seem equally motivated to wait for a large reward than normal weight controls. Although this task was never used before in childhood obesity research, we hypothesised about possible explanations. Earlier research has pointed at the importance of effective attention deployment in the regulation of delay behaviour. Differences between children may be more remarkable when the task is long, thereby challenging their motivation. The overweight children tested here may have been able to persist in the short waiting periods in the present experiment. In real life situations, when gratification is typically delayed for longer periods, the strategies used by overweight children may not facilitate long-term self-control. Future research should be directed at determining the attention deployment strategies and the subjective experience of children in the delay task, particularly perceived task difficulty and reported level of frustration.

These results confirm the earlier findings from Nederkoorn and colleagues (Nederkoorn et al., 2006). The Nederkoorn study assessed the same impulsivity paradigms, but looked within each at only one process. They also found that overweight children performed worse on both the inhibition of a prepotent response (Stop Task) and on the gambling task (Door Opening Task). The results of both the Nederkoorn study and the current investigation are of interest because they reveal which specific inhibitory processes display deficits and may burden the self-regulatory skills in overweight children.

Limitations of the current study hamper generalisation of the findings. First, the current findings may not be easily generalisable due to the potential risk of selection bias of a clinical-based sample. Second, the reward-directed tasks are never 'pure' measures of a single impulsivity process but are related to a number of processes. Third, since executive function measures are strongly related to IQ, controlling for IQ in future research is recommended. In general, performance improves with higher IQ (Mahone et al., 2002). Since all children attended regular schools, we

\section{Behaviour Change}


assumed that none of them had severe intellectual deficits. Finally, the assumed link between lacking inhibitory processes and obesity related eating behaviour is not researched here. Now that the psychological processes associated with impulsivity in overweight children have been identified, future research can explore how the eating behaviour of overweight children is related to impulsivity or lack of self control.

In sum, the present study was the first to use a multidimensional approach in the investigation of impulsivity in overweight children. It replicates and further elaborates the findings of Nederkoorn and collegues (2006). Interestingly, overweight children seem to show more reward-directed behaviour and lack inhibitory skills on some, but not all, tasks. Obesity treatment programs can develop specific techniques for helping overweight children to master effective and specific inhibitory skills as well as to strengthen their ability to resist temptation and delay gratification.

\section{References}

Agranat-Meged, A.N., Deitcher, C., Goldzweig, G., Leibenson, L., Stein, M., \& Galili Weisstub, E. (2005). Childhood obesity and attention deficit/hyperactivity disorder: a newly described comorbidity in obese hospitalized children. International journal of Eating Disorders, 37, 357-359.

Avila, C., Cuenca, I., Felix, V., Parcet, M-A., \& Miranda, A. (2004). Measuring impulsivity in school-aged boys and examining its relationship with ADHD and ODD ratings. Journal of Abnormal Child Psychology, 32, 295-304. Impulsivity in adults: Motor inhibition and timeinterval estimation. Personality and Individual Differences, 6, 133-136.

Bachorowski, J-A, \& Newman, J.P. (1985). Impulsivity in adults - motor inhibition and timeinterval estimation. Personality and Individual Differences, 6, 133-136.

Bachorowski, J-A, \& Newman, J.P. (1990). Impulsive motor behaviour: Effects of personality and goal salience. Journal of Personality and Social Psychology, 58, 512-518.

Barkley, R.A. (1997). Behavioural inhibition, sustained attention, and executive functions: Constructing a unifying theory of ADHD. Psychological Bulletin, 121, 65-94.

Bonato, D. P., \& Boland, F.J. (1983). Delay of gratification in obese children. Addictive Behaviour, $8,71-74$.

Bourget, V., \& White, D.R. (1984). Performance of overweight and normal-weight girls on delay of gratification tasks. International Journal of Eating Disorders, 3, 63-71.

Braet, C., Claus, L, Verbeken, S., \& Van Vlierberghe, L. (2007). Impulsivity in overweight children. European Child and Adolescent Psychiatry, 16, 473-483

Braet, C., \& Crombez, G. (2003). Cognitive interference due to food cues in childhood obesity. Journal of Clinical Child and Adolescent Psychology, 32, 32-39.

Brewerton, T.D., Hand, L.D., \& Bishop Jr., E.R. (1993). The Tridimensional Personality Questionnaire in eating disorder patients. International Journal of Eating Disorders, 14, 213-218.

Bullik C.M., Sullivan, P.F., Weltzin, T.E., \& Kaye, W.H. (1995). Temperament in eating disorders. International Journal of Eating Disorders, 17, 251-261.

Castellanos F.X, Sonuga-Barke, E.J.S., Milham, M.P., \& Tannock, R. (2006). Characterizing cognition in ADHD: beyond executive dysfunction. Trends in Cognitive Sciences, 10, 117-123.

Daugherty, T.K., \& Quay, H.C. (1991). Response perseveration and delayed responding in childhood behaviour disorders. Journal of Child Psychology and Psychiatry, 32, 453-461.

Davis, C., Strachan, S. \& Berkson, M. (2004). Sensitivity to reward: implications for overeating and overweight. Appetite, 42, 131-138.

Davis, C., Patte, K., Levitan, R., Reid, C., Tweed, S., \& Curtis, C. (2007). From motivation to behaviour: A model of reward sensitivity, overeating, and food preferences in the risk profile for obesity. Appetite, 48, 12-19.

Dawe S., \& Loxton, N.J. (2004). The role of impulsivity in the development of substance use and eating disorders. Neuroscience and Biobehavioural reviews, 28, 343-351. 
Dougherty D.M., Bjork, J.M., Harper, R.A., March, D.M., Moeller, F.G., Mathias, C.W., et al. (2003). Behavioural impulsivity paradigms: A comparison in hospitalized adolescents with disruptive behaviour disorders. Journal of Child Psychology and Psychiatry, 44, 1145-1157.

Dougherty, D.M., Mathias, C.W., Marsh, D.M., \& Jagar, A.A. (2005). The laboratory behavioural measures of impulsivity. Behaviour Research Methods, 37, 82-90.

Dreessen, L., Stroux, A., \& Weckx, M. (1998). Nederlandse vertaling van het Gestructureerd Klinisch Interview voor DSM-IV - kind versie (KID-SCID; Versie 1.0) [Dutch translation of the Structured Clinical Interview for DSM-IV Child edition]. Maastricht, The Netherlands: Author.

Engel, S.G., Corneliussen, S.J., Wonderlich, S.A., Crosby, R.D., le Grange, D., Crow, S., et al. (2005). Impulsivity and compulsivity in Bulimia Nervosa. International Journal of Eating Disorders, 38, 244-251.

Fassino, S., Daga, G.A., Piero, A., Leombruni, P., \& Rovera, G.G. (2001). Ane rand personality in eating disorders. Journal of Psychosomatic Research, 51, 757-764.

Fassino, S., Leombruni, P., Piero, A., Daga, G.A., Amianto, F., \& Rovera, G. (2002). Temperament and character in obese women with and without binge eating disorder. Comprehensive Psychiatry, 43, 431-437.

Fredriks, A.M., van Buuren, S., Wit, J.M., \& Verloove-Vanhorick, S.P. (2000). Body index measurements in 1996-7 compared with 1980. Archives of Diseases in Childhood, 82, 107-112.

Geurts, H.M., Verté, S., Oosterlaan, J., Roeyers, H., \& Sergeant, J. A. (2004). How specific are executive functioning deficits in attention deficit hyperactivity disorder and autism? Journal of Child Psychology and Psychiatry. 45, 836-854.

Guerrieri, R., Nederkoorn, C., \& Jansen, A. (2007). How impulsiveness and variety influence food intake in a sample of healthy women. Appetite, 48, 119-122.

Guerrieri, R., Nederkoorn, C., Stankiewicz, K., Alberts, H., Geschwind, N., Martijn, C., et al. (2007). Appetite, 49, 66-73.

Gunstad, J., Paul, R.H., Cohen, R.A., Tate, D.F., Spitznagel, M. B., \& Gordon, E. (2007). Elevated body mass index is associated with executive dysfunction in otherwise healthy adults. Comprehensive Psychiatry, 48, 57-61.

Hien, D., Matzner, FJ., First, M.B., Spitzer, R.L., Gibbon, M., \& Williams, J.B.W. (1994, 1998). Structured Clinical Interview for DSM-IV - Child edition (Version 1.0). New York: Columbia University.

Hollingshead, A. (1975). Four factor index of social status. New Haven, CT: Yale University Press.

Hollingshead, A.B., \& Redlich, F.C. (1958). Social class and mental illness. New York: John Wiley \& Sons.

Holtkamp, K., Konrad, K., Muller, B., Heussen, N., Herpertz, S., Herpertz-Dahlmann, B., et al. (2004). Overweight and obesity in children with attention-deficit/hyperactivity disorder. International Journal of Obesity, 28, 685-689.

Johnson, W.G., Parry, W., \& Drapman, R.S. (1978). The performance of obese and normal size children on a delay of gratification task. Addictive Behaviour, 3, 205-208.

Kindlon, D., Mezzacappa, E., \& Earls, F. (1995). Psychometric properties of impulsivity measures: temporal stability, validity and factor structure. Journal of Child Psychology and Psychiatry, 36, 645-661.

Kuntsi, J., Stevenson, J., Oosterlaan, J., \& Sonuga-Barke, E.J.S. (2001). Test-retest reliability of a new delay aversion task and executive function measures. British Journal of Developmental Psychology, 19, 339-348.

Lewitts, D.J., \& Israël, A.C. (1978). Maintaining children's ongoing delay of gratification through other-oriented consequences. Developmental Psychology, 14, 181-182.

Lijffijt, M., Kenemans, J.L., Verbaten, M.N., \& van Engeland, H. (2005). A meta analytic review of stopping performance in attention-deficit/hyperactivity disorder: Deficient inhibitory motor control? Journal of Abnormal Psychology, 114, 216-222.

Logan, G.D., \& Cowan W.B. (1984). On the ability to inhibit thought and action: A theory of an act of control. Psychological Review, 91, 295-327.

\section{Behaviour Change}


Logan, G., Cowan, W., \& Davis, K. (1984). On the ability to inhibit simple and choice reaction time responses: A model and a method. Journal of Experimental Psychology and Human Perceptual Performance, 10, 276-292.

Lyke, J.A., \& Spinella, M. (2004). Associations among aspects of impulsivity and eating factors in a nonclinical sample. International Journal of Eating Disorders, 36, 229-299.

Mahone, E.M., Hagelthorn, K.M., Cutting, L.E., Schuerholz, L.J., Pelletier, S.F., Rawlins, et al. (2002). Effects of IQ on executive function measures in children with ADHD. Child Neuropsychology, 8, 52-65.

Manly, T., Anderson, V., Nimmo-Smith, I., Turner, A., Watson, P., \& Robertson, I.H. (2001). The differential assessment of children's attention: The Test of Everyday Attention for hildren (TEA-Ch), normative sample and ADHD performance. Journal of Child Psychology and Psychiatry, 42, 1065-1081.

Matthys, W., van Goozen, S.H.M., de Vries, H., Cohen-Kettenis, P.T., \& van Engeland, H. (1998). The dominance of behavioural activation over behavioural inhibition in conduct disordered boys with or without attention deficit hyperactivity disorder. Journal of Child Psychology and Psychiatry and Allied Disciplines, 39, 643-651.

Matthijs, W., van Goozen, S.H.M., Snoek, H., \& van Engeland, H. (2004). Response perseveration and sensitivity to reward and punishment in boys with oppositional defiant disorder. European Child and Adolescent Psychiatry, 13, 362-364.

Matzner, F., Silva R.R., Silvian, M., Chowdhury M., Nastasi, L. (1997). Preliminary test-retest reliability of the KID-SCID. Paper presented at the American Psychiatric Association Meeting.

Matzner, F. (1994). Videotapes as training tools for the development of the KID-SCID. Paper presented at the American Academy of Child and Adolescent Psychiatry, 42nd Annual Meeting, Washington DC, United States.

Nasser, J.A., Gluck, M.E., \& Geliebter, A. (2004). Impulsivity and test meal intake in obese binge eating woman. Appetite, 43, 303-307.

Neef N.A., Marckel, J., Ferreri, S.J., Bicard, D.F., Ende, S., Aman, M.G., et al. (2005). Behavioural assessment of impulsivity: a comparison of children with and without attention deficit hyperactivity disorder. Journal of Applied Behaviour Analysis, 38, 23-37.

Nederkoorn, C., Van Eijs, Y., \& Jansen, A. (2004). Restrained eaters act on impulse. Personality and Individual Differences, 37, 1651-1658.

Nederkoorn, C., Braet, C., Van Eijs, Y., Tanghe, A., \& Jansen, A. (2006) Why obese children cannot resist food: The role of impulsivity. Eating Behaviour, 7, 315-322.

Nederkoorn, C., Jansen, E., Mulkens, S., \& Jansen, A. (2007) Impulsivity predicts treatment outcome in obese children. Behaviour Research and Therapy, 45, 1071-1075.

Nederkoorn, C., Smulders, F.T.Y., Havermans, R.C., Roefs, A., \& Jansen, A. (2006). Impulsivity in obese women. Appetite, 47, 253-256.

Nichols, S.L., \& Waschbusch, D.A. (2004). A review of the validity of laboratory cognitive tasks used to assess symptoms of ADHD. Child Psychiatry $\mathcal{E}$ Human Development, 34, 297-315.

Nigg, J.Y. (2000). On inhibition/disinhibition in developmental psychopathology: Views from cognitive and personality psychology and a working inhibition taxonomy. Psychological Bullitin, 126, 220-246.

Ogden,C.L., Kuczmarski, R.J., Flegal, K.M., Mei, Z., Guo, S., Wei, R., et al. (2002). Centers for Disease Control and Prevention 2000 growth charts for the United States: Improvements to the 1977 National Center for Health Statistics version. Pediatrics, 109, 45-60.

Oosterlaan, J., \& Sergeant, J.A. (1998). Response inhibition and response re-engagement in attention-deficit/hyperactivity disorder, disruptive, anxious and normal children. Behaviour Brain Research, 94, 33-43.

Oosterlaan J., Logan, G.D., \& Sergeant, J.A. (1998). Response inhibition in AD/HD, CD, comorbid $\mathrm{AD} / \mathrm{HD}+\mathrm{CD}$, anxious, and control children; a meta-analysis of studies with the stop task. Journal of Child Psychology and Psychiatry, 39, 411-425.

Reilly, J.J. (2006). Tackling the obesity epidemic: new approaches. Archives of Disease in Childhood, $91,724-726$.

Reilly, J.J. (2007). Childhood obesity: An overview. Children and Society, 21, 390-396. 
Rosval, L., Steiger, H., Bruce, K., Israël, M., Richardson, J., \& Aubut, M. (2006). Impulsivity in women with eating disorders: Problem of response inhibition, planning, or attention? International Journal of Eating Disorders, 39, 590-593.

Ryden, A., Sullivan, M., Torgerson, J.S., Karlsson, J., Lindroos, A.K., \& Taft, C. (2003). Severe obesity and personality: a comparative contriolled study of personality traits. International Journal of Obesity, 27, 1534-1540.

Schachar, R., Logan, G.D., Robaey, P., Chen, S., Ickowicz, A., \& Barr, C. (2007). Restraint and cancellation: Multiple inhibition deficits in attention deficit hyperactivity disorder. Journal of Abnormal Child Psychology, 35, 229-238.

Scheres, A., Oosterlaan, J., Swanson, J., Morein-Zamir, S., Meran, N., Schut, H., Vlasveld, L., et al. (2003). The effect of methulphenidate on three forms of response inhibition inboys with AD/HD. Journal of Abnormal Child Psychology, 31, 105-120.

Solanto, M.V., Abikoff, H., Sonuga-Barke, E., Schachar, R., Logan, G.D., Wigal, T., Hechtman, L., et al. (2001). The ecological validity of delay aversion and response inhibition as measures of impulsivity in ADHD: A supplement to the NIHM Multimodal Treatment Study of ADHD. Journal of Abnormal Child Psychology, 29, 215-228.

Sonuga-Barke, E.J.S. (1994). On dysfunction and function in psychological theories of childhood disorder. Journal of Child Psychology and Psychiatry, 35, 801-815.

Sonuga-Barke, E.J.S. (2003). The dual pathway model of AD/HD: An elaboration of neuro-developmental characteristics. Neuroscience and Biobehavioural Reviews, 27, 593-604.

Sonuga-Barke, E.J.S., Taylor, E., Sembi, S., \& Smith, J., (1992). Hyperactivity and delay aversion I. the effect of delay on choice. Journal of Child Psychology and Psychiatry, 33, 387-398.

Ryden, A., Sullivan, M., Torgenson, J.S., Karlsson, J., Lindroos, A-K., \& Taft, C. (2003). Severe obesity and personality: A comperative controlled study of personality traits. International Journal of Obesity, 27, 1S34-1S40.

Timbremont, B., Braet, C., \& Dreessen, L. (2004). Assessing depression in youth: Relation between the Children's Depression Inventory and a structured interview. Journal of Clinical Child and Adolescent, 33, 149-157.

Van den Bos, R., \& De Ridder, D. (2006). Evolved to satisfy our immediate needs: Self control and the rewarding properties of food. Appetite, 47, 24-29.

Van den Bree, M.B.M., Przybeck, T.R., \& Cloninger, C.R. (2006). Diet and personality: Associations in a population-based sample. Appetite, 46, 177-188.

Vila, G., Zipper, E., Dabbas, M., Bertrand, C., Robert, J. J., Ricour, C., \& Mouren Siméoni, M.C. (2004). Mental disorder in obese children and adolescents. Psychosomatic Medicine, 66, 387-394.

Wang, Y., \& Lobstein, T. (2006). Worldwide trends in childhood overweight and obesity. International Journal of Pediatric Obesity, 1, 11-25.

Wilson, E. (1980). Delay of gratification in overweight and normal weight children. Dissertation Abstracts, 40, 3429-3430.

Wilson, N., \& Evans, I. (2002) Relationship between reward-dominant response style and ratings of boys conduct problems. New Zealand Journal of Psychology, 31.

\section{Behaviour Change}

